\title{
Bloodstream infections caused by multidrug-resistant non-fermentative bacilli in southern of Poland in 2013
}

\author{
A Chmielarczyk', M Pomorska-Wesołowska², M Pobiega, G Ziółkowski, D Romaniszyn', J Wojkowska-Mach \\ From 3rd International Conference on Prevention and Infection Control (ICPIC 2015) \\ Geneva, Switzerland. 16-19 June 2015
}

\section{Introduction}

Modern medicine requires a clear and explicit criteria to describe the phenomena of public health; and one of the major problems of public health is drug resistance of microorganisms.

\section{Objectives}

The aim of this study was to analyze how big epidemiological problem are highly-resistant - multidrugresistant (MDR) and extensively-drug resistant (XDR) non-fermentative bacilli isolated from bloodstream infections (BSI) in southern Poland.

\section{Methods}

The study comprised consecutive, non-repetitive nonfermentative bacilli (NFB) isolates received by the Chair of Microbiology UJCM with collaborative 2 laboratories in 2013 from BSI of hospitalized (12 hospitals) throughout south of Poland (Malopolska and Silesia).

Studied strains from BSI were belonging to groups: ACI (Acinetobacter baumannii $\mathrm{n}=21$, Acinetobacter lwoffii $\mathrm{n}=1$, Acinetobacter ursingi $\mathrm{n}=1$ ), PAR (Pseudomonas aeruginosa $\mathrm{n}=12$ ), and others (Stenotrophomonas malthophilia $\mathrm{n}=10$, Achromobacter denitrificans $\mathrm{n}=5$, Comamonas testosterone $\mathrm{n}=1$, Ochrobactrum anthropi $\mathrm{n}=1$ ).

Antimicrobial susceptibility was assessed according to current EUCAST guidelines. Different patterns of resistance were defined according to Magiorakos (2012) as: MDR strains or XDR.

\section{Results}

NFB strains occurred with different frequencies, the highest prevalence was associated with ACI: 1.3\%.
More than $75 \%$ of ACI strains were resistant to 14 out of 16 antimicrobials, among ACI also found the highest share of XDR: $95.7 \%$. The most of these isolates were resistant to all antibiotics with the exception of colistin: MIC50 for colistin was 1 .

In the group of PAR isolates $91.7 \%$ were XDR, MIC50 for colistin was 1 .

DiversiLab typing demonstrated the presence of two dominant ACI clones. Clone 1 and clone 2 , both are classified as the European clone 2 (EUII).

\section{Conclusion}

The presented data indicate a high potential therapeutic problems related to the large resistance of ACI isolates. The used stratification of drug resistance (MDRO/XDR/ PDR) may become an important tool for the assessment of public health and microbiological hazards at different levels. (supported by DEC-2012/05/B/NZ7/02880).

\section{Disclosure of interest}

None declared.

\section{Authors' details}

${ }^{1}$ Jagiellonian University Medical School, Kraków, Poland. ${ }^{2}$ Department of Microbiology, Analytical and Microbiological Laboratory, Korlab Nzoz, Ruda Slaska, Poland. ${ }^{3}$ Higher School of Medicine in Sosnowiec, Sosnowiec, Poland.

Published: 16 June 2015

doi:10.1186/2047-2994-4-S1-P138

Cite this article as: Chmielarczyk et al:: Bloodstream infections caused by multidrug-resistant non-fermentative bacilli in southern of Poland in 2013. Antimicrobial Resistance and Infection Control 2015 4(Suppl 1):P138.

TJagiellonian University Medical School, Kraków, Poland

Full list of author information is available at the end of the article 